\title{
New ruralities and centralities for rural development
}

\section{Introduction: rural enclosures and urban domestications}

It is common to assume that in the second demographic transition, argued to have begun around 1950, the world is becoming less rural. By 2007 more than 50 per cent of the world's population was urban, even though the developing world still remains more rural than urban. Countries like the US, Canada, Sweden, Australia, China and Japan have experienced or are experiencing a severe decline, with 'attractive' urban living standards being seen as the major cause. The majority of countries in the world experienced rapid decreases in rural populations between 1981 and 2016. This was especially the trend in newly industrializing and urbanizing countries in East and South Asia, Latin America and parts of Africa. The rural population of China has decreased by 45.9 per cent during the past 35 years, whilst the figure in Brazil has almost reached 60 per cent (Li et al., 2019).

Increasingly it would seem that the burgeoning numbers living in urban areas, and indeed many of these in the intermediate suburban areas surrounding these expanding city regions, are experiencing, we can argue, a new process of cosmopolitan domestication. This has of course been a feature since early industrialization in 19th-century Europe, but by the middle of the 20th century it had become a dominant and mass demographic shift. By the start of the 21st century the world had witnessed a scale of con-urbanization that was unprecedented, with urban population densities increasing whilst becoming, at the same time, more dependent upon distanced rural resources (such as foods, energy and minerals). People are continuing to lose their rural roots, identities and ways of living as they become re-domesticated in urban - 'post-natural' environments that make them, somewhat paradoxically, even more dependent upon complex supply chains and services in order for them to survive (see Scott, 2017). 
In turn, and importantly, many new urban dwellers lose the wherewithal and the skills to self-procure as they become increasingly reliant on purchasing commodified and manipulated goods and services. Urban domestication is often taken for granted as a sign of 'progress', and indeed progressive modernization, part of the 'knowledge economy' and successful economic growth. It historically and in a contemporary sense of course tends to demand more commoditization of life, as opposed to self-provisioning and self-sufficiency. Naturally this is a highly variegated process and certainly hides high levels of differentiated urban-rural relations.

We want to suggest here that this massive and historically unique process currently underway places rural development in a significantly re-located and critical position. The highly conglomerated and interconnected cities of China, for example, become increasingly dependent upon rural-based resources, not least rocks and minerals. A hundred miles west of Shanghai, one can witness the devastation of rural hills and mountains, quarried for their urban building materials. Around many more established cities (like London or Sao Paulo) vastly extended food supply chains spread not only to their geographically close rural hinterlands, but also to internationalized importing platforms for fresh fruits and vegetables (such as the Sao Francisco valley in North East Brazil, or the rural heartlands of Ghana). Rural people not only move temporarily or permanently to these cities, but even if they stay on in their rural heartlands many become affected by the urban and cosmopolitan insatiable demands for rural-based resources. Thus we have to recognize that the age of urban cosmopolitanism comes with new human and cultural processes of rural development, urban re-domestication and, indeed, rural enclosure. These twin processes become a major feature of global rural development, as we shall see.

As Li et al., 2019 (p140) comment:

Rural decline is an inevitable process associated with the transformation from an agrarian to the urban-industrialized economy, and further on to the knowledge economy. However, rural decline is not pre-destined. It is by the interactions between rural areas and the external environment that rural communities either grow, decline or even vanish. How rural evolution proceeds depends upon the capacity of the rural communities, which respond to external changes through adjusting their internal components and structure. In this process, rural communities of different geographical conditions, natural resource endowments and social relationships, as well as people's values, attitudes and institutions will make different responses, which finally lead to different evolution patterns and outcomes.

Given then an ongoing process of what we might term 'urban domestication', it now seems that significant differences may be occurring between the 
expanding and densely living urban and the more sparsely populated rural peoples. For instance:

- Mortality in the South at least tends to be higher in rural areas than in urban areas, largely owing to higher mortality of children under the age of five. This stems from many rural areas having lower incomes, poorer nutrition, less clean water and sanitation, and fewer medical services than their urban counterparts. But this is a mean observation, and as we know urban domestication is recreating many health disadvantages (higher obesity, higher vulnerability to non-communicable diseases like diabetes, high rates of water and air contamination, and higher rates of anti-microbial vulnerability) (ODI, 2016).

- Fertility in rural areas also tends to be higher than in urban areas. That may also be a function of lower incomes, but may be associated with agriculture too, since it is easier for mothers to combine child raising and farm work compared with working in a factory - and the children tend to help on the farm from an earlier age.

- The combination of higher mortality and fertility can delay the process of urban domestication so that rates of natural population growth can be higher in rural areas, although most rural areas in the South experience out-migration to the cities, such that these grow proportionately faster.

- Without migration out of rural areas, the higher natural rates of population growth in rural areas would tend to ruralize rather than urbanize countries. Migration is thus essential for continuing and fuelling the process of urban domestication; and it seems that at least under current carbonized systems of economic growth, without urbanization, economic 'growth' would be severely impaired.

- Urban domestication can, especially for women and girls, bring improved living and reproductive standards, and is leading to higher levels of aggregate carbonized energy use, creating far larger ecological 'footprints' in the all-consuming cities. As urban domestication implies far higher levels of consumption, and correspondingly lower levels of direct participation in production (e.g. of energy and foods, etc.), surrounding rural hinterlands become critical for supply and equating this spatial and ecological dependency.

- If more and more of us are to varying degrees effectively 'domesticated urbanists', i.e. we are locked into path-dependent lifestyles and consumption patterns not of our own making, what effects does this have: (i) on existing rural areas and peoples; (ii) on urban people's resilience or vulnerability; and (iii) on creating opportunities or obstacles for post-carbonized forms of transformation? In short, how will the current demographic fix play out once it is realized that the agglomerative economic and cultural 
advantages of the city no longer apply? And what does this suggest to us about the re-calibration of rural and urban livelihoods? Is not the triumphalist 21st-century city not fit for purpose as the world strives towards post-carbonism? Should we not at the very least seriously question the extreme processes of urban domestication that have been unleashed (especially since 1950), and indeed the profound spatial fixes upon which this process has depended?

- Of course experiences of social inequality, poverty and social exclusion are now rife in both urban and rural settings. But it remains a stark fact that migrations to the city are often an expression of desperation and distress in rural living standards, whilst return migration (especially in the North) is often associated with a quest to retain non-urban domesticated ways of living for the urban relatively rich and successful.

- Today rural-urban relations are at something of a turning point: will the urbanization trend that has risen from 20 per cent in 1960 to 46 per cent in 2014 continue in the face of wholesale transformations in our use of energy, material resources, and food supplies? What will be the main pathways towards more sustainable forms of rural development given that, more than ever, they will have to be the bases for producing and generating these forms of renewable and bio-spherical natural resources? Will we undergo a 'third demographic transition' with huge dispersals of now urban-domesticated populations re-occupying rural hinterlands? Will rural areas face new forms of 'urban-based enclosure' where their resources are appropriated under conditions of more extreme resource depletion for the purposes of satisfying stronger states and hegemons?

\section{Urban domestication, rural enclosure and pathways to empowerment}

Now we can begin to draw what some might regard as a new societal and cultural dichotomy between the urban and the rural in the context of our current global and indeed globalizing ecological and economic crisis. This does not of course suggest that the rural and the urban are disconnected. They are quite the opposite, in that they increasingly 'feed off each other'. The purpose of this first chapter of the volume, then, is to conceptually re-ask important sociological and geographical questions, such as, what is it like to be urban; what is it like to experience rurality? What is the nature of rurality in post-modern society when hyper-mobilities collide with new ecological vulnerabilities and social inequalities? And, importantly, do these conditions engender a new 
transition to re-territorialized and, as Latour (2018) suggests, re-territorialized processes as a reaction to global and globalized ecological and economic crisis? Somewhat ironically, rural places again become places to put down roots, almost as an antidote to globalization and ecological crisis.

Further chapters in this book will attempt to explore some of these major cardinal points in this new rural-urban compass and consider key aspects of the academic research agenda as we progress (or indeed re-gress) into the post-carbonized transition, during a period when the coherence and perhaps dominance of the neo-liberal hegemony is now, at the very least, fragmenting (see Tilzey, 2019). Clearly we argue here in this chapter that it is possible to posit that the process of urban or metropolitan domestication has and continues to be a global and somewhat universal process affecting not just urban populations but those in many rural areas as well. Access to diverse consumption patterns, high levels of mobility, the opportunities choice brings, tend now to be accounted as a global universal. In rural areas, however, the dangers are that the very demands that such (urban) domestications place on natural resources significantly affect rural areas.

This is most commonly witnessed by the recent round of rural 'land grabbing' - or the new enclosures. Since 2007, an estimated 220 million hectares has been acquired by foreign investors in the global South (see Chapter 5). Intensive forms of increasingly vulnerable urban domestication are being offset by more intensive and profound forms of financialized enclosure in many rural regions, especially those areas - such as in Africa and Latin America - where pre-existing rules and governance regimes are relatively weak to resist these financialized pressures (Chapter 4). Whilst much has been made of the new rounds of 'land grabbing' as new expressions of hyper-financialization and the expression of 'accumulation by dispossession' (Harvey, 2003) by extracting and exporting primary natural resources, it is also the case that this is indeed a by-product of the intensive process of urban domestication being experienced in countries like China, the majority of South Asian countries and (food and water insecure but rapidly urbanizing) Middle Eastern oil states. Expanding and densely populated cities rely upon vast and increasing ecological and indeed rural 'footprints'. It is argued that London's is the equivalent size of Spain. But this is of course a generality and a metaphor. In reality, cities lie at the epicentres of immense and complex supply chains for natural and processed resources, like water, rocks, minerals, foods and plants and animals.

Thus intensive forms of urban domestication are going hand in hand with selective and intensive forms of new rounds of rural enclosure, now on a globalized scale. Just as the early urban manufacturing cities demanded former 
rural labour and resource commodification and enclosures in the 18th and 19th centuries, in the 21st this has massively intensified with networks of mega-cities demanding globally extractive enclosures across the globe. See for instance the development of China's 'belt road initiative'. We have to recognize therefore that the growth of mega-urbanization is coming at an increasingly high material and ecological cost. And it is one that may not be sustainable.

If we conceive of mega-urban domestication and rural enclosures as 'two sides of the same coin' at least in hyper-capitalist and carbonist hegemonic systems, this also begins to raise questions of who is enslaving whom, and who is empowering whom? Or to put it another way: what types of power and empowering relations are these interdependencies creating? Not all rural areas are caught up in webs of extractive enclosure, with many (in Western Europe, for instance), it would seem, able to create more autonomous systems of empowerment that enable endogenous social and economic development to take hold. Similarly, in the midst of the big 'high rise' city we find counter-hegemonic forces developing, not least around access to sustainable foods, housing and energy schemes. Indeed the spectre of post-carbonism shows some signs of also encouraging post-capitalist and certainly post-neo-liberal modes of social organization and profit sharing that are 'counter-hegemonic' in that they create the social conditions for social empowerment over consumerist 'enslavement'. Hence we begin to witness counter-movements in both the urban and rural realms, and indeed, as with the food solidarity movements in Brazil and Southern Europe, new emancipatory urban-rural relations that are disrupting our earlier domestication-enclosure dialectic.

We can conceive of this as not so much 'accumulation by dispossession' as new forms of empowerment by association. The latter tendency is becoming a more dynamic force in many urban and rural settings and is creating new innovative conditions for social action and sustainability strategies in many rural regions. Hence empowerment by association can be considered a transformative force, as we shall discuss in Chapter 3, not least around agroecology and new empowered urban food consumption (Chapter 6). People can, as the transition from capitalist carbonism accelerates, find the space and social power to create new associations and practices that are based upon different and more emancipated forms of organization. Hence the city is not merely a site of domestication and disempowerment, just like the countryside is not merely a place of enslavement or enclosure. Therefore, the complex unfolding of the tendencies for both domestication and enclosure now have to be modified and qualified by considering how new sites and networks of association and empowerment can take hold. 
Thus in writing this volume we have realized (at the particular vantage point of 2020) that we are witnessing a time when both traditionally exploitative tendencies of urban domestication and rural enclosure are indeed intensifying and diversifying. But, at the same time, we can recognize the power of alternatives and transformative processes counterposing these tendencies. This, we argue, throws up many contradictions and dilemmas for contemporary rural peoples and areas. We wish, in a non-reductionist and open-ended way, to explore these tendencies, as the contradictions and dilemmas play out; and to propose some of the key epistemological and methodological questions and challenges these raise for those engaged in rural (as well as urban) research.

\subsection{Interlinked systems of urbanized/consumerist domestication and rural enclosure}

Nowhere are the linkages and mutual dependencies and vulnerabilities involved in urban re-domestication and rural enclosure more exposed than in the fast-urbanizing (and so-called developing) regions of South and East Asia. In 2014 the WTO estimated that 422 million adults were living with one of the four most prevalent non-communicable diseases (NCDs). In most countries, including Malaysia, this prevalence is increasing. Addressing the key interconnected risk factors for Type 2 diabetes - unhealthy diets, obesity and physical inactivity - is critical in understanding and attempting to tame this rising trend (see Schema, 2017). In turn this requires radical reshaping of urban lifestyles and environments, and it is indeed a recent wave of re-domestication that is highly negative to urban people's health and wellbeing. Let us consider the case of Malaysia, a rapidly urbanizing and developing country that is emerging from its more rural and traditional past.

Diabetes is a major and rising health concern in urban Malaysia, affecting almost one in five Malaysian adults (Li et al., 2019; Lee, 2020). By 2025, 7 million adults are projected to have developed diabetes. Frequency of and opportunities for unhealthy fast food choices are seen as a major cause of this recent growth. Food choices are influenced by convenience and cost. The pressures of urban life, work demands, traffic congestion, and the rise of urban dual-income households have all led to a decline in home cooking and self-provisioning. Now 64 per cent of Malaysians eat at least one meal per day outside the home. Time pressures also reduce the willingness or energy to seek outlets serving healthier food, with many making choices based on time and costs alone. On top of this structural and potentially addictive trend, the average consumption of sugar in Malaysia is 26 teaspoons per day (2005), more than four times the recommended allowance. A large fraction of this sugar comes in the form of local 'kuih', often consumed with meals and as 
snacks throughout the day, and imported condensed milk, added to tea and coffee.

The popularity of fast food and the now rapid expansion of outlets has especially affected food choices of Malaysian youth. On the one hand, fast food reflects a desire for convenience, and a reduced appreciation of traditional food choices; on the other, accessible affordable fast food increases habituation to unhealthy diets. This is reinforced by fast food advertising and commercials and television programming aims at children. This feeds addiction (like the morning greetings from a fast food giant that tempt road users along a busy highway in the Klang Valley).

Obesity has tripled worldwide since 1975, reaching epidemic proportions in both developing and developed countries; as of 2018, 13 per cent of adults are obese and 39 per cent overweight. Meanwhile, the prevalence of overweight and obesity among children and adolescents has risen from 4 per cent in 1975 to 18 per cent in 2016. The Global Burden of Disease Study (Ng et al., 2014) reported a prevalence of overweight and obesity in Southeast Asia of 22.1 per cent among men and 28.3 per cent among women, with the highest rates in Malaysia at 48.3 per cent and 48.6 per cent for men and women, respectively. The 2015 Malaysian National Health and Morbidity Survey (NHMS) reports similar numbers, estimating the national prevalence of overweight and obesity in adults at 30.0 per cent and 17.7 per cent, respectively, for a total of 47.7 per cent. In just two decades, the prevalence of overweight adults has almost doubled from 16.6 per cent, while obesity has increased approximately four-fold from 4.4 per cent (Institute of Public Health, 1996).

Malaysia has stated its intent to stop the rise in prevalence of obesity by 2025 (Ministry of Public Health, 2016). The US\$1-2 billion (RM4.26-8.53 billion) spent to combat obesity in 2016 - including direct and indirect costs - is equivalent to $\sim 10-19$ per cent of national healthcare expenditures. Public health messages around nutrition - such as those issued by the Malaysia Health Promotion Board - are important as one of a range of efforts for health promotion and obesity prevention. Yet, despite all these actions, obesity rates have continued to rise sharply.

Failure to halt the dramatic increase in the prevalence of overweight and obesity in Malaysia and worldwide has contributed to increased health risks for NCDs such as diabetes, cardiovascular diseases and cancers and other health issues, leading to higher morbidity and mortality rates. About 8 per cent of total mortality each year is attributed to obesity. Beyond increased risk of obesity-related chronic diseases and poorer quality of life, the healthcare 
costs of treating obesity-related disease conditions are rapidly escalating. On average, obese Malaysian males and females lose 6-11 years and 7-12 years of productive life, respectively.

It is important to consider how health messages feed into the urban physiological-environmental system that underlies obesity and the conditions necessary for information to be effective in this context. Public health messages aimed at reducing obesity must transcend an implied information-deficit model, which assumes that supplying basic knowledge on nutrition is enough to achieve change. Rather, such messages are best understood as attempts to convince a very broad, diverse audience to make behavioural and lifestyle changes that are both difficult and at odds with their contextual cues and incentives. This differs from traditional marketing, which delivers uncomplicated, attractive messages to targeted audiences, and it should be no surprise that health messages achieve lower response rates. This problem is compounded when health-sector messages compete against those from commercial and corporate food and 'health' industries. The latter promote simpler products while also generating profits, allowing the private sector to far outspend the health sector in this context. At present, guidelines for health promotion focus on communication techniques, such as limiting the number of ideas to avoid confusing readers, reducing jargon and technical language, using active voice and conversational style, and providing concrete examples. Indeed, beyond failing to enable healthier behaviour, poorly crafted messages may contribute to negative self-perceptions and, in the process, generate more pervasive problems. Yet, while important, such techniques do not address the broad range of obstacles in the messaging environment.

As knowledge is necessary, but not sufficient, to change behaviour, messages targeted at individual behaviour need to be accompanied by strategies that create contexts where people are encouraged or naturally predisposed to act on these messages. Therefore, health communicators also need to consider how to influence the key actors who shape these environments. For example, the failure of town and transport planners to consider health issues in, for instance, the design of parks, recreation centres, and other public spaces has been seen as a cause of the rise in the prevalence of obesity, NCDs, and sedentary behaviour. A wide range of stakeholders-both public and private, at federal, state, and municipal levels-must play a role in halting the obesity crisis. Physical, social and cultural environments associated with work, food, family, and community all enable and constrain the individual choices and behaviours that affect obesity. For example, in Malaysia, the widespread practice of serving sweet and savoury snacks at morning and afternoon tea at functions, conferences, and meetings enables over-consumption of food and cements frequent eating 
as a social norm. Working hours, availability of fast food, and school nutrition (SCHEMA, 2018), among other factors, also play key enabling/constraining roles in Malaysia. Health messages and other policy interventions must target these physical, social and cultural environments, connecting actors and creating new feedback links to reshape systems in ways that promote health.

Within Malaysia there is such heterogeneity in sociocultural environments that both the message and the way it is communicated must be tailored to local contexts, highlighting the importance of place-based thinking. Indeed, rates of obesity in Malaysia vary by geographical locations and ethnicity, and these differences are greater than can be explained by simple urban/rural differentiation. Varied diets and cultures imply that the changes needed to achieve healthy and socially acceptable eating habits and lifestyles may be very different for different ethnic and social groups. Similarly, identifying the appropriate form of messages and messengers for a target group is important and requires local knowledge. Acquiring and using this knowledge depends on early and consistent community engagement and participation in both research and policy processes, before problems and potential solutions are formulated. Accounting for the particularities of place will better allow for the development of targeted and tailored messages, programmes, guidelines, and interventions to meet age, gender, culture, socioeconomic, and geographical needs.

\subsection{Impacts on rural enclosures: examples in Malaysia}

The growth in both urban population and dietary changes is having important implications for Malaysian farming and rural food systems. The government, faced with growing costs of imports of basic foods (meat, milk and sugar), is promoting a domestic policy of self-sufficiency. This entails large-scale restricting of some small family farming areas, and the development of largely scale-intensive livestock units. This in turn entails subsidies for high-tech intensive systems to feed growing urban populations and meet the needs of the growing population (of 50 million by 2050). Across much of Southeast Asia this is a familiar story; and indeed we can see here a direct linkage between the reconstituted and unhealthy dietary changes principally occurring in the cities, and the policies of new rural enclosures both at home and abroad that attempt to supply these dietary changes. The intensive livestock industry is also highly dependent upon the procurement of global feedstocks, not least soya and corn based. The reconstitution of the Malaysian diet then becomes a major driver for 'locking in' intensive systems of enclosure both in Malaysia and abroad.

This is currently, despite significant recent policy pronouncements advocating more sustainable diets and production practices (see EAT-Lancet Report, 
Planetary Health: Jan 2019), the major development trend in the Malaysian and Southeast Asian agri-food complex, and it is tied directly to an urban and mega-urban model of growth and modernization that, as we see here, creates and re-creates a range of negative feedbacks for urban and rural populations alike. In addition, this re-domestication of urban people holds different social and physical consequences for different ethnic and demographic groups and is also highly gendered. Risks and vulnerabilities are both intense but also highly differentiated across the cities and the countrysides. Bodies and lives are literally re-shaped by these processes, and obesities and diabetes are increased based upon the generation of addiction to particular unhealthy food choices and related car-based lifestyles.

When scholars and policy advocates talk about transforming such systems, then, it is important to stress the high levels of cultural and social 'lock-in' such exploitative and domesticated systems tend to reproduce. This means that we should not discourage talk and ways of transforming these systems. But it also suggests, as we will posit in more detail in the succeeding chapters, that we have to understand the very (post-modern) ways in which domestication and habituation works and has been re-created in urbanized and rural populations, if we are to realistically bring about real transformations and new empowerments.

Here, as Scott (2017:21) historically reminds us, such re-domestications are not un-linked to the role of the state and governance systems (see Chapter 2). Following Aristotle he conjectures that states have always relied on various forms of enslavement and bondage: 'The captives, individually and collectively, become an integral part of the state's means of production and reproduction, a part, if you will, along with livestock and grain fields'. City walls, for Scott, were a symbol not so much of keeping the barbarians and invading peasants out, as an infrastructure for enslaving and keeping a fiscal and hegemonic control of those increasing masses who resided within.

\subsection{Reflecting on the urban to understand the rural}

In the contemporary (especially con-urban) world the boundaries between freedom and captivity are far more complex than recognized in antique periods, but the questions of enslavement and empowerment through now complex and advanced digital and physical forms of control are no less relevant.

Take for example the relatively new use of digital facial recognition technologies. Whilst in the West these are being increasing controlled by security 
agencies and a small group of digital and social media firms (like Facebook), in the East, especially in mega-urbanizing China, they are becoming literally embodied into civil society actions by the totalitarian communist state (see Lanchester, 2019; and Strittmatter, 2019). The progress in facial recognition technologies and big data is resulting in their use not just for surveillance of popular unrest (as in the now long-running protests in Hong Kong, and indeed one of the main reasons that face masks and umbrellas have become such a crucial defence for the protestors); it is also central to the pilot trials of what are termed 'social credit systems'. This is far extending the West's use of financial credit ratings into what is seen by the state as socially desirable behaviour. Points are awarded for good behaviour, not least communist party organization, and calligraphy lessons, but lost for pouring water outside the house, dog fouling, driving through red lights, etc. In some versions your social credit scores are affected by the types of social networks with which you may be associated, as well as who you travel or congregate with, and where. As Lanchester (2019) argues:

The China-wide version of social credit is scheduled to go live in 2020. The ultimate goal is to make people internalize their sense of the state: to make people self-censor, self-monitor, self-supervise. Strittmatter quotes Discipline and Punish [Foucault] 'He who is subjected to a field of visibility, and who knows it, assumes responsibility for the constraints of power, he makes them play spontaneously upon himself; he inscribes in himself the power relation in which he simultaneously plays both roles; he becomes the principle of his own subjection'. The Chinese version of social credit is the closest thing we've ever seen to Foucault's system in action at a national level.

Social credit is currently most extremely applied in Xinjiang province to monitor and regulate Muslim minorities (Uighurs). Here people are forced to have police-owned GPS systems in their cars, you can only buy petrol after having your face scanned, and mobile phones have a state app on them to monitor their activities and prevent access to 'damaging information'. Religious activity is monitored too, and the state is able to know if you have or participate in foreign networks. DNA and fingerprints are offered in 'free health clinics'. This is a new mega-city, an algorithmic version of state-led re-domestication; and in the West it is being led not only by the state but also by de-regulated digital media companies like Facebook, which already owns patents for customers' algorithmic representations of their faces, and members of their networks' faces. Today, in 2020, this is increasingly what it's like to be urban.

Certainly the rise of urban-based non-communicable diseases, diet-related human health risks, and more intensive expressions of air and water pollution are relatively new forms of urban enslavement that are in turn built upon 
a density-driven and convenience-driven urban consumption re-domestication of both household and work life. It is argued that pollution of water systems creates conditions also for the rise in urban neighbourhoods of anti-microbial resistance and infertility. High-density and 'high-rise' living come with renewed risks too (consider the example of Grenfell Tower in the richest borough in London), especially as income and social inequalities rise in these dense urban and increasingly privatized spaces (see Chapter 5). Indeed, as Bai et al (2012:465) have scientifically synthesized from a planetary health and human ecology standpoint:

The health risks associated with the urban environment are diverse. Many cities face at least five types of health threats: (i) [i]nfectious diseases that thrive when people are crowded together in sub-standard living conditions; (ii) [a]cute and chronic diseases such as respiratory disease and pulmonary cancer that are associated with industrial pollution; (iii) [c]hronic, non-communicable diseases that are on the rise with unhealthy lifestyles (physical inactivity, unhealthy diets, tobacco smoking and harmful use of alcohol; (iv) injuries resulting from motor vehicle collisions, violence and crime, and (v) climate change related health risks, for example heat stress and changed patterns of infectious disease, which are considered as one of the biggest health risks in the 21 st century and are likely to exacerbate existing risks.

Air pollution has re-emerged as a global urban killer. In the US, it is estimated that it kills up to 200,000 people per year, more than traffic accidents, and combinations of outdoor and indoor air pollution caused one in every nine deaths globally in 2016, far more than those caused by malaria, malnutrition or alcohol (Gardener 2019). Beijing's intense smog in January 2013 (dubbed the 'Airpocalypse') sparked wider political awareness of our urbanized dependence upon burning coal, gasoline, diesel, wood and litter. London is not only one of the most unequal cities in Europe; it also has the worst nitrogen dioxide pollution level in Europe. The Mayor in 2016 declared the city a 'public health emergency' and announced a new 'ultra-low' emission zone for Central London. Climate change as expressed in more 'wild fires' in the US and the San Francisco Bay area, meant that this iconic city region had, in 2018, the worst air quality in the world, easily on a par with what the inhabitants of Delhi experience day on day. This is a form of ecological and biological urban enslavement and embodiment.

Exposure to fossil exhaust particulates can result in the particulates' penetrating deep into the lungs, and into the alveoli, the tiny air-filled sacs where oxygen is exchanged for carbon dioxide. The particulates then travel into the bloodstream and throughout the body, lodging themselves on the brain, constricting arteries, creating heart attacks and strokes. This can affect the unborn as well as vulnerable persons such as children and the elderly. In 2019, despite 
significant denial lobbying and rubbishing of the science by fossil fuel industries and their political supporters, the American Lung Association reported that 141 million Americans live with unhealthy levels of ozone and particle pollution, an increase of 7 million since 2018. This is attributed to the exacerbating effects of climate change. Ambient air pollution is now responsible for 8.8 million premature deaths per year, more than double previous global estimates, and 1.5 million more than caused by smoking.

We can see here, then, that in the context of both climate change, and a long and contested denial by fossil fuel business interests, urban living is, for many, an enslavement process involving high levels of metabolic and biological vulnerability, created and re-produced by an increasingly dense and polluting ambience that restricts dwellers' environmental rights to natural and (what should be) 'common pool resources' (see Chapter 5). This is seemingly exacerbated by not only the growing privatization of available green spaces in cities, but also the still largely unregulated nature of air and water pollution.

Our points here are not just to dwell upon the relatively new pathologies and domestications of urban life, but to demonstrate the relationships and discontinuities these trends have with and for their surrounding countrysides, and in turn concerning rural development (see UN Habitat, 2019). The trends tend to de-naturalize urban living and the urban condition, which means that many people, especially inner-city residents, have no or little access to direct forms of nature: they are indeed naturally and ecologically enslaved. This is, of course, very different from the rural condition, however much some rural places are also populated with larger numbers of urban cosmopolitans. For the richer urban cosmopolitans, such denaturalized urbanities drive various forms of 'counter-urbanization', expansive suburbanization and what Americans call 'white flight', either temporarily (as exotic forms of tourism), or more permanently in the buying of second or new first rural homes. These are trends well established in the richer countries and are also being replicated in Asia and parts of Latin America. Thus the reactions by many urbanites who can afford it, are to escape the enslavements of urban life, and to re-create a rurality that holds all of the advantages of the city culture.

Growing and increasingly recognized pathologies of urban life are leading to a variety of rebound and interactive effects in rural development; and so we need to tease out the new dynamic linkages between the urban and rural worlds in times of growing ecological and economic crisis, and a period when the sanctity of the urban 'growth machine' needs to be seriously called into question. One implied question becomes, therefore, if new models of (post-carbonized) growth and modernity are to be designed, how will this affect 
our understanding of what rural areas are for? And what forms of rurality can be experienced? So far few have considered the implications of a post-carbon world on the countrysides. Yet we can see here that what happens in the rural domain is intricately bound up with growing global cosmopolitanism, and all of its ecologically driven 'spill-over' effects. These become major drivers for rural change and development, far more nuanced now than in previous centuries of nationalistic colonialism and enslavement. This in many ways sets a context to ask new agrarian questions about how rural development copes with global cosmopolitanism.

\section{Transversal rural development themes: empowerment and association}

These global and variable post-modern trends, we believe, create a fertile research ground and agenda in which to explore the new geographies of empowerment and association in rural areas. Up until recently it was generally assumed that generalized capitalist relations have penetrated most of the globe - North and South. With the rise of neo-liberalism in recent decades, many have assumed that rural agricultural producers are subject to the same fundamental forces of capitalist markets, leading to the decline in pre- or post-capitalist modes of production. Byres (2012) calls this a sort of 'world system determinism', with conclusions drawn without close spatial analysis of the internal dynamics of agriculture and its interactions with a range of related production, and without taking account of the particularities of property relations that govern local production systems (see Carlson, 2017:718). Recent evidence suggests that in the Global South at least many regions do not

appear to be following the general processes of dispossession and differentiation that occurred with the transition to capitalism in the Global North. It would appear that there is still an unresolved agrarian question in the Global South today, and that it remains central to understanding the problem of underdevelopment. The exact nature of this question, however, can only be understood through a more detailed analysis of the rural property relations that govern agriculture in the vast array of societies that make up the Global South. (Carlson, 2017:718)

In the global North too, the persistence of family farms, even if they are reduced in number, and the disproportionate number of small businesses is a strong feature of advanced rural regions. In the EU, the State has attempted to protect the family farm whilst also encouraging the rise of agri-business and corporate retailing. Many rural areas are fostering new social relations of production as well as pre-existing systems, leading again to a more complex 
picture than that depicted in 'world systems' or global food regimes thinking. We can hypothesize that with both the continuing crisis of neo-liberalism and its attendant global assumptions about subsuming traditional forms of production and property rights, and the process of post-carbonism, there will be conditions for further fundamental differentiation of rural production systems. First, there is the traditional but rising trend towards farm-based pluri-activity, which suggests a diversification as well as a re-empowerment of family-based businesses in the rural domain; and second, we also now witness the growth of the agri-energy-tourism nexus (see Marsden and Rucinska, 2019), whereby, as demand inevitably increases for energy and amenity from rural resources, 'farms' become sites for a variety of natural resource, energy and amenity production. In the global South too, in China and Brazil, eco-tourism and amenity provision become significant drivers of rural development, especially around the hinterlands of the expanding cities, and as the domesticated urban middle classes 'rediscover' the need for natural habitus as well as urban habitus. Again the re-constitution of the urban-rural relation, now under conditions of neo-liberal crisis and post-carbonized transition, becomes a critical factor in restructuring the rural realm and, indeed, creating opportunities for differentiated empowerment of rural people, not least the young and the female.

Rural areas are thus facing new processes of reconstitution (see Murdoch and Marsden, 1995), which are shaping their social spaces and locales. This is not contradictory to the continued processes of mega-urbanization, the shifts towards post-carbonism, or the rise of (domesticated, and urban) environmentalism, which in itself creates more demands for rural goods and services, from sustainable foods, natural amenity spaces, agri-tourism, and links and experiences with the rural 'exotic'.

These processes are re-shaping rural areas and indeed making them more aligned and influenced by their particular regional settings. Whilst national and globalized networks and assemblages have a key role in many rural regions (see Woods, 2018) in shaping rural empowerments and enclosures, so too do the local and regional contexts in which these rural regions sit. The relational geographies of rural spaces are made up of combinations of shorter and longer connections, depending upon the nature of the reconstituted socio-natural endowments those rural areas hold. It is this essential process of contingent uneven and combined development that creates the social conditions for their continued survival and/or vulnerability. Natural and physical ecological endowments come to take a renewed significance in the post-carbon transition, not only because they may become attractors for urban amenity and environmental interests, but also because those very physical ecologies become the bedrock upon which more sustainable production and consumption 
practices can be developed. No clearer case here demonstrates this than, as we discuss in Chapter 6, the rise of agro-ecologies, which in themselves have to be situated and develop and be defined from their own ecological geographies. Similarly, the location of wind turbines, hydro-energy schemes, bio-gas and composting initiatives, solar energy sites, can only be created where there are inherent natural endowments. Thus in the post-carbon transition, relational space meets natural space, such that they are recombined to create sustainable rural development. One cannot exist without the other.

We can see here, then, that the rise of these tendencies and combined complexities of post-modern rural-urban realities tends to confront somewhat outdated or out-moded theoretical and conceptual frameworks upon which we have hitherto relied. 'World system determinism' and its attendant connections with agrarian 'regime theory' seem unable to capture the temporalities, differentiations or spatialities now arising. In a similar vein, after two decades of post-structuralist application in the social sciences, and the particular approaches associated with social constructionism and post-humanism, we now see the need, once again, to combine our nuanced understandings of relational space with the realization that nature, as bio-physical and ecological nature, and natural endowments really matter in the post-carbonized transitions (Clark, 2011). Thirdly, the distinctive nature of rural transformations has so far not been incorporated sufficiently into transitions management theories of change. In subsequent chapters in this volume, therefore, we do not wish to completely debunk these theoretical avenues. Rather we wish to use them as creative springboards to develop new and, we think, more relevant contemporary theoretical positions - positions, indeed, that are needed in order for us to understand the complexities of contemporary rural and urban living and livelihoods.

Thus it seems apposite at the current juncture, and in writing about the unfolding research agenda for global rural development, to point to a need to develop new and potentially more grounded theoretical frameworks that can assist scholars and researchers in their endeavours to understand the potentialities and challenges of rural living on a turbulent and increasingly con-urbanized planet. In this sense the new and revised 'agrarian question' is much broader than its original conception, which was associated with the long-running question of, why does 'backward'-facing agriculture represent a fundamental barrier to industrialization and economic development and progress in societies? Also, why does it seem an obstacle to fully fledged capitalist penetration of agriculture and rural relations? Whilst we may argue that these questions are still of relevance (indeed both in the South and the North), the central question today needs reformulating around the global necessity to assess how rural and 
agricultural societies can contribute to a (largely urban domesticated) world that is fast running out of material resources for its continued existence, and faces growing climate change vulnerabilities that exacerbate these unsustainabilities. Our answer, as we wish to expand, is that the rural, and rurality, will be fundamental in meeting these challenges of post-carbonized modernization and transformation; perhaps in part because it never completely allowed the appropriation of its natural and social assets in earlier phases of capitalist development. Thus the new agrarian question is far from just a concern about understanding its inherent 'backwardness', as it involves tracing its potentialities for sustainable transformations and innovations.

\section{Conclusions: refracting the rural-urban dichotomy for the 21 st century}

In Sorokin and Zimmerman's classic, Principles of rural-urban sociology and Systematic Source Book (1929-32), the authors synthesized and reflected on over forty years of investigative rural and urban studies by concluding:

Our general conclusion must be that all the principal differences between rural and urban societies - differences in means of communication, in mobility, occupation, total population, and density - are tending to diminish. Rural and urban societies ... are approaching a type of rurban society .... Under the influence of steam-power civilization, the two societies became radically different. The use of electricity, however, and such recent inventions as the radio and the automobile have begun to produce a rapprochement that in all probability will develop. [volume 7, p642 and quoted by Granberg (2018)]

These conclusions promoted ongoing fierce debates about the existence or otherwise of a rural-urban continuum, and/or the conceptual redundancy of the 'rural-urban dichotomy' under the conditions of 20th-century progressive modernism (see Granberg, 2018; Andersson et al. 2016). We have argued here, a century on, that rural and urban societies are far more interconnected and diverse; and yet to be rural, or to be urban as we have seen above, can hold very different experiences and life chances. Urban living creates new pathologies for many, with new forms of domestication and environmental enslavement, far more profound than the 'densities' and 'heterogeneities' commented upon by Louis Wirth (1938) in his Chicago of the 1930s. Rural development today, as we struggle towards a post-industrial and post-carbonized world, represents both a site of potential continuing enclosure (e.g. of exclusive houses, landed estates, exploitative and intensive practices) and of a new socio-cultural and ecological enlightenment - a place for the potential re-creation and empower- 
ment of social autonomy and participatory community by association (Milone et al. 2015).

The next chapters - on governance, power and transformations, financialization, land and property, agroecology, family farming, and markets - will explore these deep rural dilemmas, tensions and contradictions, these new 'agrarian questions', in more substantive detail. It is important to conclude, then, that global rural development today represents both a scholarly and re-politicized sociological potential, essentially a new framing that could and can obviate many of the destructive and unsustainable cosmopolitan forces that continuing capitalist, often authoritarian, and industrialized con-urbanism still manufactures and exudes. 
Terry Marsden, Claire Lamine, and Sergio Schneider - 9781788974196 Downloaded from PubFactory at 04/26/2023 10:47:51AM via free access 